\title{
NEW TECHNOLOGIES FOR 3D REALIZATION IN ART AND DESIGN PRACTICE
}

\author{
Peter Walters \& Paul Thirkell, University of the West of England, Bristol, UK
}

\begin{abstract}
As digital design technologies become ever more widespread, CAD-CAM, virtual and rapid prototyping techniques are increasingly being exploited by creative practitioners working in areas outside the industrial design and engineering contexts in which these technologies are currently predominantly employed. This review paper aims to critically examine work by artists, craft practitioners, and designer-makers who creatively engage with these new and rapidly emerging technologies and, by doing so, extend their own practice and push at the boundaries of art and design disciplines. Historic precedents for new 3D technologies in the fine and applied arts are identified, and writing by Heidegger, Baudrillard, and Virilio informs the critical review of work by art and design practitioners in sculpture, metalwork, jewellery, and ceramics. The discussion reflects on relationships between art and technology and physical and virtual making, and concludes by pointing to the possibility of new "hybrid" forms of practice which bridge the gap between physical and virtual design worlds. The paper closes by suggesting that the notion of "truth to materials" in the arts and crafts might now be extended to one of "truth to virtual materials", as practitioners creatively negotiate relationships between digital cause and physical effect.
\end{abstract}

Keywords: Keywords: digital, hybrid, physical, prototyping, virtual, 3D scanning

\section{INTRODUCTION}

This paper critically reviews creative applications for CAD-CAM ${ }^{1}$ and rapid prototyping technologies, focusing upon areas of practice which lie outside the industrial design and engineering contexts in which these technologies are currently predominantly employed. The review identifies examples of work by art and design practitioners who are expanding boundaries in terms of applications for the technologies, and opening up new possibilities and perspectives on creative practice.
The review takes the premise that practitioners in art and design who are free from the constraints of designing for industrial manufacture may adopt approaches to new design technologies that are conceptually different from those employed by industrial designers and engineers. In this way, art and design practitioners are able to develop novel strategies and processes which seek to challenge and even subvert accepted standards in software and hardware applications.

Early adopters of computer-aided design and prototyping technologies included engineers in the aeronautical and automotive manufacturing sectors (Jacobs, 1992). In design and manufacturing industries, CAD-CAM, virtual and rapid prototyping have been referred to as "time compression" 2 technologies since, through their use, industrial designers and engineers aim to accelerate new product development timescales by reducing the requirement for traditional prototyping techniques. Proponents of the new technologies argue that it may be both feasible and desirable to reduce and in some cases eliminate traditional hands-on making and manuallyoperated machining methods which can be both costly and time-consuming.

Within an industrial context, new prototyping technologies can be viewed as being a "means to and end", since here the physical or virtual prototype serves as a stepping-stone on the way towards a manufactured item. In design and engineering applications, virtual and/or rapid prototyping are often used to simulate (at various levels of fidelity and with varying degrees of success) some or all of the characteristics of a yet-tobe-manufactured product or system.

The industrial paradigm of time compression may appear to be at odds with the creative practice of those artists, craft practitioners and designer-makers whose work embodies processes of craft mastery: the acquisition of practical skills, "tacit knowledge" ${ }^{3}$ and material sensibilities, taking place within "the workshop of 


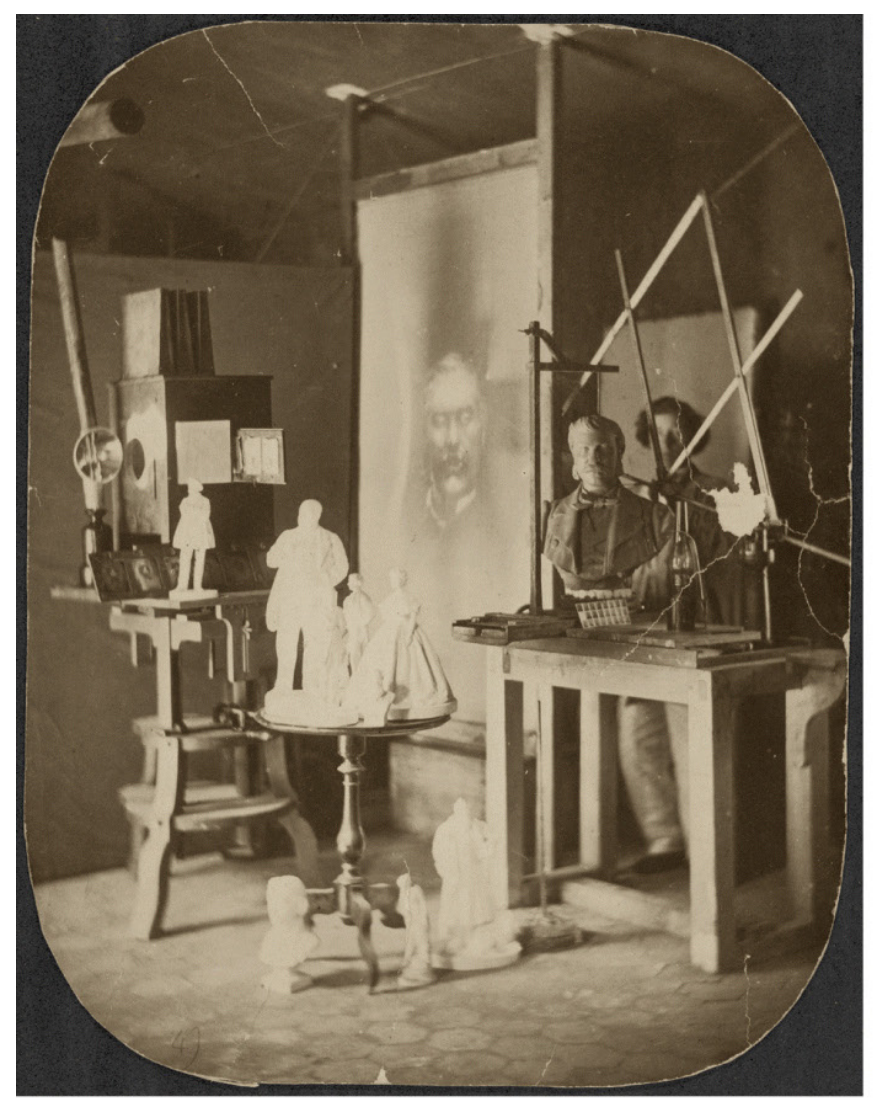

(a)

Figure 1a.

François Willème, Photosculpture Studio, c. 186367. Courtesy George Eastman House. A further illustration showing Willème's photosculpture process can be found on the Early Visual Media website (Weynants, 2008).

long experience and incessant practice" (Heidegger, 1951, p. 158). Through reflective practice involving the direct manipulation of physical material, these creative practitioners are intimately engaged in the production of finished artefacts rather than prototype simulations. However, it is clear from the examples which follow that the new technological processes have qualities and characteristics which are perceived by practitioners as having value in their own right, rather than being considered merely as a means to an end, or a way of producing a simulation of something yet-to-exist. Examples are drawn from across the art and design disciplines, ranging from sculpture and ceramics to metalwork and jewellery. These examples of innovative practice demonstrate the imaginative application of new prototyping technologies through an intimate understanding of technical and aesthetic possibilities, resulting in creative outcomes which push at the boundaries of art and design disciplines.

This paper first identifies some historic precedents to rapid prototyping which may be found in nineteenthand early twentiethcentury art practice. The critical

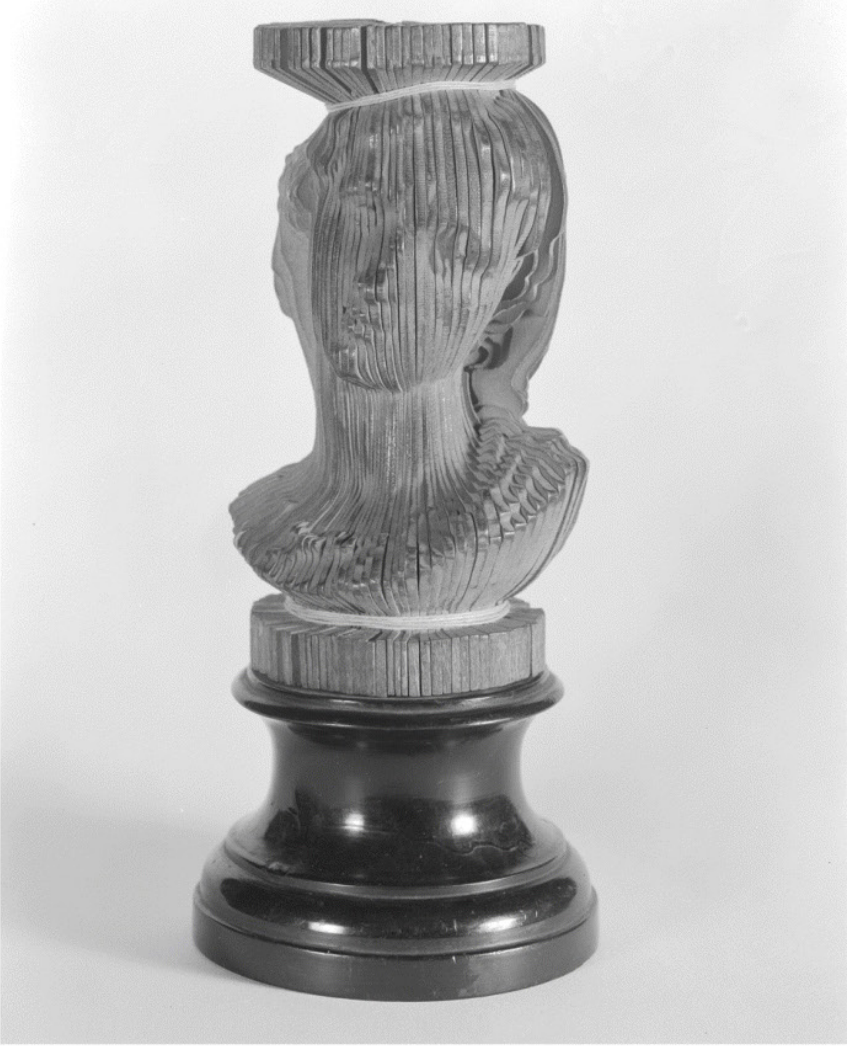

(b)

Figure $1 \mathrm{~b}$.

François Willème, Portrait of a Woman, c. 1860. Oak Maquette composed of profiles made from photographs. Courtesy George Eastman House.

context for the review is introduced, drawing on the writing of Heidegger, Baudrillard and Virilio, and the paper then proceeds to introduce examples drawn from contemporary creative practice in art and design which demonstrate a range of novel applications for computeraided design and prototyping technologies.

\section{HISTORICAL PERSPECTIVE: PRECEDENTS TO RAPID PROTOTYPING IN THE FINE AND APPLIED ARTS}

With the aim of increasing the speed and efficiency of new product development processes, developments in rapid prototyping technologies to date have predominantly focused on applications in engineering and industrial design. It may therefore seem surprising to discover techniques developed by nineteenth- and early twentieth-century practitioners in the fine and applied arts which are in some ways analogous to new technologies such as 3D scanning and rapid prototyping employed today. Beaman et al. (1997) have identified a number of examples of such techniques, which include the process of "Photosculpture" developed in France in the 1860s by Franc, ois Wille'me, and also a 
“Photographic Process for the Reproduction of Plastic Objects", for which Carlo Baese filed a United States patent in 1904.

The technique of "mechanical sculpture" or "photosculpture" (Figure 1) was developed as an attempt to produce three-dimensionally accurate physical replicas of people or objects with only a minimal requirement for handwork, and also to enable sculptures
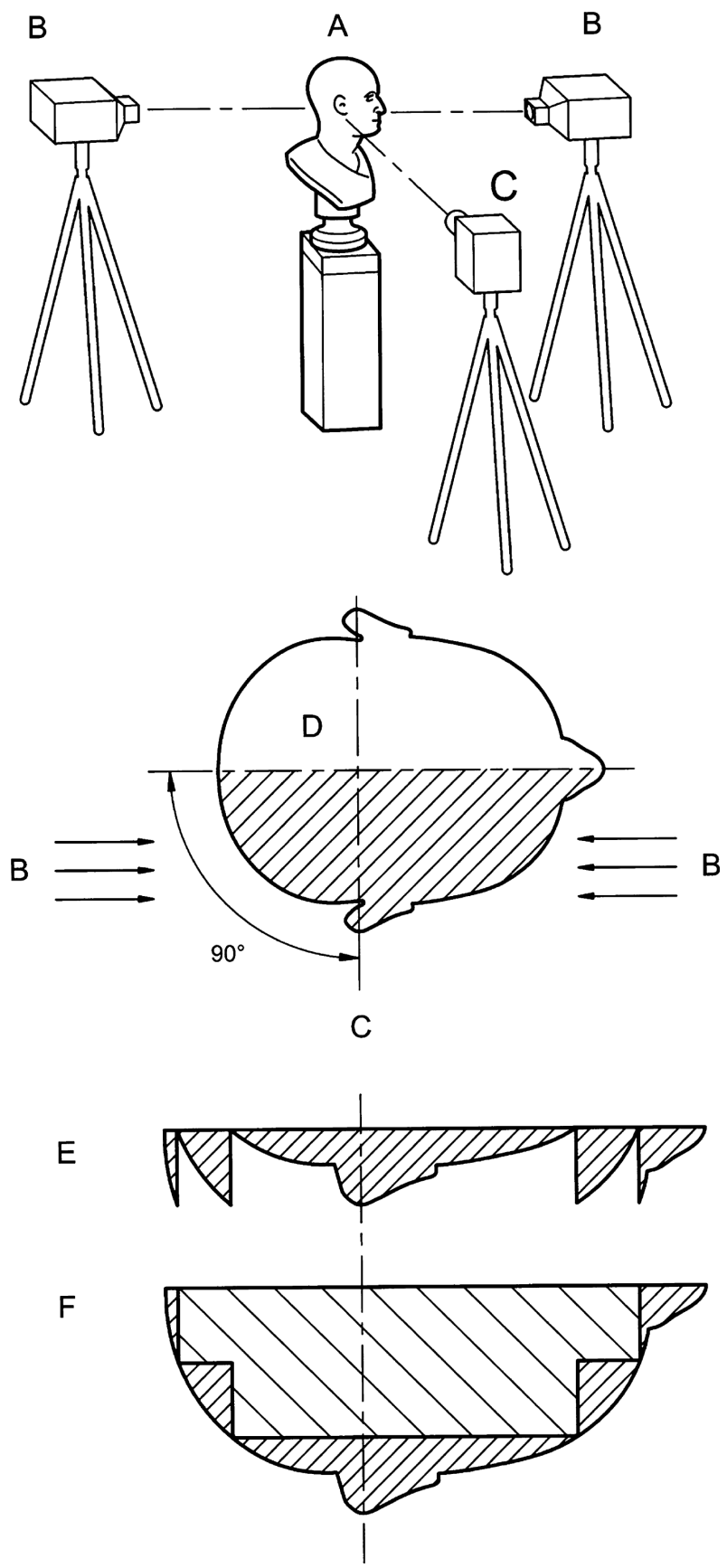

Figure 2

Carlo Baese: Photographic Process for the Reproduction of Plastic Objects, US Patent 774,549: 1904

(a) bust form to be reproduced; (b) projectors illuminating bust front and rear with graduated light; (c) camera; (d) plan section through bust; (e) gelatine sections after expansion reproducing shape of bust; (f) gelatine sections on stepped support. Drawings after extracts from the Patent document. to be duplicated at low cost. In this process the subject of the sculpture - a person or object - was placed in the centre of a circular room. The subject was then photographed by 24 simultaneously operating cameras positioned equally around the circumference of the room. Each of 24 photographic silhouettes of the subject could then be projected onto a screen and traced using a pantograph mechanism attached to a cutting tool. This device was used by an artisan to cut a wooden profile for each of 24 radial segments which, when assembled, formed the finished sculpture (Beaman et al., 1997; Sobieszek, 1980).

Beaman et al. note that the hand-cutting stage of Wille'me's photosculpture could still considered to be a relatively labour-intensive process. In an attempt to eliminate this stage from the reproduction process, Carlo Baese proposed a technique for reproducing physical objects that employs a photo-sensitive gelatine which expands in proportion to its exposure to light.

In Baese's technique, described in his patent specification of 1904, a bust or other object to be reproduced is photographed whilst being illuminated with graduated light, so as to achieve maximum depth of contrast (Figure 2). Photographic plates are then produced, through which light is exposed onto photosensitive gelatine. When treated with water, the photosensitive gelatine material expands to form a relief corresponding to the three-dimensional shape of the bust.

As suggested earlier, the techniques described in these historic examples might be considered to be to some extent analogous to today's 3D scanning and rapid prototyping (3D printing) technologies. 3D scanning is used capture data describing the physical shape of existing artefacts. Common non-contact 3D scanning techniques employed today include laser scanning, structured light scanning, and silhouette scanning. In laser scanning, a laser beam is projected onto the surface of an object. Light from the laser is reflected back from the object to a camera on the scanner. The laser is used to accurately determine the distance from the scanner to the object. 3D shapes are typically captured by repeated scanning at many different angles and positions across the surface of an object. Data captured in this way are used to construct a "point cloud" corresponding to the shape of the object. In structured light scanning, a pattern of light such as a line or grid is projected onto an object. A camera captures the deformation of the pattern as it is projected onto the object's surfaces, and software uses this information 
to construct the 3D shape of the object. In silhouette scanning, the external outlines of an object are captured in a series of photographs taken from different angles around the object. Software is used to translate these external outlines or silhouettes into a 3D model approximating the shape of the object.

In design and engineering, data captured through 3D scanning is commonly employed in "reverse engineering" processes (Milroy et al., 1996), and also to input into 3D CAD modelling software for design applications. For example, Unver et al. (2006) describe how 3D scanning can be used by automotive designers to capture the shape of hand-made clay models, created when exploring complex surface forms for vehicle designs. In this way data from the hand-made physical prototype can be imported into 3D CAD for further design development.

Rapid prototyping enables a physical prototype to be obtained as an output from a virtual model created in $3 \mathrm{D}$ CAD software. In rapid prototyping physical objects are built layerby- layer by computer-controlled machinery, typically in one of the following processes: Stereolithography (SL) in which photo-sensitive resin is solidified by a laser; Selective Laser Sintering (SLS) in which metal or plastic powder is fused together by a laser; Fused Deposition Modelling (FDM) in which an extruded filament of molten polymer fuses and solidifies as it cools; and Powder-Binder 3D Printing (e.g. Z-Corp) in which plaster powder is bonded together using a printable binder.

Of course, the most obvious difference between the historical examples cited earlier and the prototyping technologies now available is that the techniques developed by Wille'me and Baese only enabled the re-creation of items which already existed. Rapid prototyping, on the other hand, enables the physical realization of entirely new objects, which artists, designers or engineers have constructed in virtual reality using 3D CAD software. The examples included in this paper represent a range of applications for CAD-CAM and rapid prototyping technologies within contemporary art and design practice. Taken together, they demonstrate the arguably unprecedented possibilities afforded by the new technologies. Yet commentators on the impact of new technology within creative practice have not always been so optimistic, and this critical dimension is now introduced into the discussion, to inform the review of examples which then follows.

\section{CRITICAL CONTEXT: ART AND TECHNOLOGY - THE DANGER AND THE SAVING POWER}

Some early critics of computer-aided design feared that the introduction of the new technologies posed a threat to human creativity, and would also result in the loss of valuable tacit knowledge of physical materials and processes possessed by skilled makers. For example, within engineering design, Mike Cooley (1980) asserted:

The feel for the physical world about us is being lost due to the intervention of computerized equipment and work is becoming an abstraction from the real world ... knowledge has been abstracted away from the labour process and has been rarefied into mathematical functions ... In my view, profound problems face us in the coming years due to this process. $(1980$, pp. 4, 5$) 4$

Cooley's concerns over "computerized" technologies aimed at increasing the productivity of the manufacturing industries are transposed by Press into the discourse of art and design practice and education. For example, regarding professional practice in graphic design and the emergence of so-called "mac operator" positions, Press argues that: "The designation of 'Mac Operator' positions within the design industry is a sign of the deskilling, the Taylorisation of design activity predicted by Cooley" (Press, 1996, p. 95). Here it is suggested that through this process of deskilling, the creativity of human beings might be curtailed as they are "reduced to a sort of beelike behaviour, reacting to the systems and equipment specified for them" (Cooley, 1980, p. 100).

Cooley's book Architect or bee: The human/technology relationship was in many ways a prescient work, and his views on the virtualization of design processes appear to anticipate the rhetoric of the "hypermodern" cultural theorists Paul Virilio and Jean Baudrillard. Virilio, an artist, architect and cultural critic, is known for his strongly voiced concerns relating to the human impact of rapidly emerging technologies, including virtual reality and realtime global information and communication systems. According to Virilio's arguments, these technologies have the effect of compressing time and distance, and also blur the boundaries between physical and virtual worlds, leading to a progressive digitization of human sensory experience: "the decline of immediate sensations, the analogue resemblance between what is close at hand and comparable would yield primacy to the numerical probability alone of things distant - of all things distant. And would in this way pollute our sensory ecology once and for all" (Virilio, 2000, p. 114). 
These, it is claimed, are the problematic characteristics of "hyper-reality", in which a computer-generated world might appear to be more real than reality itself. The distinction between reality and simulation becomes blurred, and "holding on to material reality becomes a near impossible task" as reality disappears before our very eyes, a tendency which has been referred to as "the theft of reality - the perfect crime" (DeGrandpre, $2001 \mathrm{p}$. 22). As Baudrillard asserts:

Virtuality only gives possibilities virtually, while taking back the reference and density of things, their meaning. It gives you everything, and subtly, surreptitiously it takes everything away at the same time. (1996, n.p.)

It has been argued that virtual design technologies deprive creative makers of the valuable practical knowledge and embodied experience that may be developed through direct manipulation of physical artefacts and materials. For example, McCullough asserts "What good are computers, except for mundane documentation, if you cannot even touch your work?" (McCullough, 1998, p. 25).

Hardware and software manufacturers are now responding to this obvious shortcoming in virtual modelling systems. Evans (2004), Shillito et al. (2004), Sener et al. (2002) and Evans et al. (2005) report on recent developments in tactile and force feedback devices, and their potential for use by designers, artists and craft makers. Their investigations focus on the latest interface archetype - the SensAble Phantom Haptic feedback device - which comprises a pen-like interface attached to the end of an articulated mechanical arm. With the pen-and-arm interface, users are able to "feel" the external boundaries of a virtual model and, with dedicated "Freeform" software, they can carve and sculpture "virtual clay" (http://www.sensable.com; Sener et al., 2002; Evans, 2004).

Proponents of haptic feedback technologies promise palpable tactile experiences. However, others highlight the shortcomings of current devices. For example, Harvard Professor Robert Howe, a specialist in tactile feedback devices, likens force feedback technologies such as the pen-and-arm interface to the experience of "poking at the world with a stick" (in Hodges, 1998). Also, research reported by Evans (2004) and Evans et al. (2005) suggests that the Phantom interface with FreeForm software may lack the necessary control of surface continuity required within industrial design applications, whilst Walters et al. (2004) have argued that as yet such systems are unable to provide an adequate substitute for the "hands-on" experience of manipulating physical materials within the real-world workshop. So it seems that haptic feedback technologies have yet to live up to the hype. There is a case, however, for developing new craft skills with users intuiting paths that lead between the virtual and the physical, to gain tacit knowledge of digital cause and physical "hardcopy" effect.

Fears expressed by the theorists and critics cited above regarding the impact of new technologies appear in some ways to echo arguments in Heidegger's 1954 essay The question concerning technology, in which the philosopher enquires into the nature of the "essence" of technology. For Heidegger, "the essence of technology is nothing technological" $(1954$, p. 340$)$; it is not to be found in mere machines. Nor is it sufficient to say that the essence of technology lies in human activity, if those activities subjugate the human being to the constrictive existence of a cog in a machine - for here, Heidegger anticipates fears that the human being may lose itself to technology in ways which present an imminent threat to the future of humankind and the planet. Heidegger says of man "he comes to the very brink of a precipitous fall. . . "if he allows himself to be subsumed into the seemingly unstoppable mechanisms of technological progress which he himself has set in motion (Heidegger, 1954, p. 332; see also Beistegui, 2005; Bunnell, 2004).

Trapped on the treadmill of technological progress, human beings become "human resources" to be exploited. Human activity is governed by the rules of efficiency, and nature is manipulated through the application of a regulating, calculating logic "driving on to the maximum yield at minimum expense" (Heidegger, 1954, pp. 320-324; Collins \& Selena, 1999, p. 160). Here humanity faces a supreme danger (Heidegger, 1954, p. 332).

Yet as well as great danger, Heidegger argues a "saving power" may be found in technology, but only if the human being is able to grasp the essence of technology. Here he cites the German poet Hölderlin (1770-1843):

But where danger is, grows

The saving power also ...

... poetically man dwells on this earth

(Hölderlin, in Heidegger, 1954, p. 340)

Heidegger looks back to the origin of the word technology; within techne he rediscovers a lost meaning:

... techne is the name not only for the activities and skills of the craftsman but also for the arts of the mind and the fine arts. Techne belongs to 
bringing forth, to poiesis; it is something poetic. (Heidegger, 1954, p. 318)

For Heidegger, the essence of technology is to be found in "poiesis" - the processes of creation - an essential unfolding or poetic revealing. It is significant here that the word "poet" has as its origin the Greek "poiein", meaning to make.

The possibility of all productive manufacturing lies in revealing... Technology is therefore no mere means. Technology is a way of revealing. If we give heed to this, then another whole realm for the essence of technology will open itself up to us. It is the realm of revealing, i.e., of truth. (Heidegger, 1954, p. 318)

Further to this, he identifies a relationship between "techne" and "episteme": "Both words are terms for knowing in the widest sense. They mean to be entirely at home in something, to understand and be expert in it. Such knowing provides an opening up. As an opening up it is a revealing" (Heidegger, 1954, pp. 318-319). By grasping the lost meaning of techne - in poetic revealing and knowing - the human being opens up the possibility of a "free relationship" with technology. The essential unfolding of technology presents the possibility of new relationships between making, revealing, and knowing.

Moreover, Heidegger suggests that the arts have a special role to play in showing the way to the saving power which may be found in technology: "Could it be that the fine arts are called to poetic revealing? Could it be that revealing lays claim to the arts most primally, so that they for their part may expressly foster the growth of the saving power ...?" (Heidegger, 1954, p. 340; see also Beistegui, 2005; Hohl, 2006).

Operating outside industrial design and engineering contexts - where CAD-CAM and rapid prototyping technologies are predominantly employed as a means to compress time and increase the productivity of manufacturing industries - practitioners in the arts may seek to question, to challenge, and even to subvert accepted notions of "best practice" in the way the new technologies are applied, perhaps using them in ways the creators of the technologies would never have conceived.

Bunnell (2004), Harrod (2007), Jackson (2007) and Spiller (2007) describe such approaches, focusing in the main on the applied arts, crafts, and designer-maker practice. The present paper extends the discussion, including further examples from fine art practice in sculpture, demonstrating a range of novel technical processes for the realisation of $3 \mathrm{D}$ artefacts. The paper offers further scope for critical engagement and "essential reflection" (Heidegger 1954, p. 340) upon the nature and role of technology within this context.

In the examples which follow, practitioners creatively explore the new forms of making made possible through advances in computeraided design technologies for the 3 D realization of physical artefacts. In the first example, the sculptor Karin Sander employs new technologies not to create new forms but to make multiple miniature reproductions of existing ones - in this case, of people. Therefore, this artistic work appears to follow naturally on from the historic techniques of photosculpture identified earlier.

\section{REVIEW OF NOVEL APPLICATIONS FOR 3D TECHNOLOGIES IN ART AND DESIGN PRACTICE Karin Sander, Sculpture 1:9,6}

German sculptor Karin Sander employed 3D body scanning and 3D printing technologies in her 2002 artwork entitled "1:9,6" (Figure 3). In the production of this artwork, people were scanned using a 3D body scanner, and the data captured were then transmitted to a rapid prototyping machine, to print miniature replica figures at a scale of 1 to 9.6

Critics argue that Sander's work challenges classical conventions of portrait and sculpture, since through her use of new technologies the miniature figures were created automatically in a way that eliminates both traditional craftsmanship and individual artistic interpretation. The work therefore also questions notions of authorship: Sander herself describes the sculptures as self-portraits, and she even avoids influencing the poses her subjects adopt as they are scanned (Koivisto, 2007; Sander, 2007). In essence, Sander's artwork represents an automated process through which visitors to the gallery can create a threedimensional self-portrait. Yet the work arguably gains much of its power through the sheer number of miniature "people" produced in this way.

In the next example, 3D body scanning is also employed, this time as a starting point for the construction of a large-scale sculpture by the artist Antony Gormley, which comprises a complex, computer-generated structure with the human form at its centre.

\section{Antony Gormley, Quantum Cloud \\ Quantum Cloud is a large sculptural work by Antony Gormley which was completed in 1999. The sculpture}


measures 30 metres high, and stands on a platform sited in the River Thames, adjacent to the Millennium Dome in London. The sculpture has at its centre a human figure, surrounded by a cloud of randomly orientated "tendrils" (Figure 4).

A recurring theme in the work of Antony Gormley is the sculptor's own body. In a number of his artworks, Gormley has used physical casts taken from his body. For Quantum Cloud, 3D laser scans of Gormley's body provided data that were used by engineers to define the perimeter boundary of the human figure at the centre of the sculpture. "Fractal growth" software, specially written for the project by LUSAS Engineering Consultancy Services, was then used to generate the complex arrangement of members which make up the structural form of the sculpture's core. Similar software techniques were also used to define the position and orientation of the outer tendrils which form the cloud structure surrounding the human figure (Figure 5). The fractal growth software employed in the generation of the form of the artwork also provided data for engineering analysis and detail design of each of the structural members from which this complex and striking sculpture is constructed.

The following example also features threedimensional forms developed using a generative computer program, though at a smaller scale, in the creation of an experimental piece by the jeweller Jo Hayes Ward.

\section{Jo Hayes-Ward, Jewellery}

Jo Hayes-Ward is a jeweller who employs 3D CAD and rapid prototyping techniques to create jewellery and experimental artefacts. She describes her work as exploring the mathematical principles of repetition, rhythm, and geometry, and the breaking down of forms into smaller elements (Hayes-Ward, 2007). Some of

(a)

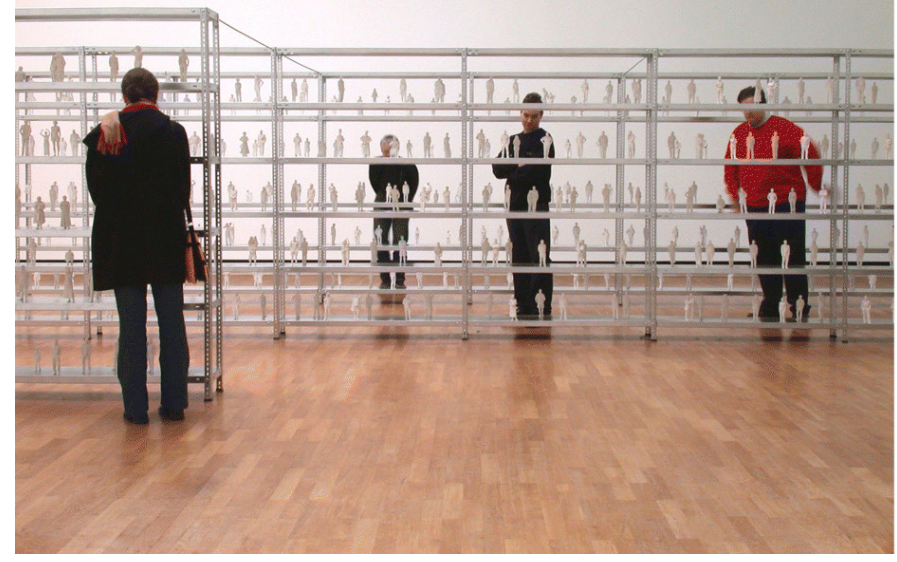

the objects she creates have the appearance of being constructed from small pixel or voxel-like ${ }^{5}$ geometric elements or cells.

In a research project conducted at the Royal College of Art in London, Hayes-Ward investigated cellular automata. These are generative systems which typically take the form of a computerized grid of cells, the status of which evolves according to mathematical rules from an initial starting configuration (Gilbert \& Troitzsch, 2005; Gardner, 1970). She utilized a cellular automaton called "Conway's Game of Life" (Figure 6) in the development of the object shown in Figure 7. The piece, which is called "Sintered City", was produced in titanium, a high-performance aerospace material, through the process of selective laser sintering. Each layer of the structure represents a generation of a $2 \mathrm{D}$ "game". The architectonic appearance of sintered city is reminiscent of some of the more extreme forms of modernist architecture, or perhaps the sculptures of Eduardo Paolozzi, which explore relationships between art and technology, or between humans and machines. ${ }^{6}$

In the bangle shown in Figure 8, the delicate structure of cubic elements was not created automatically by generative algorithms, but rather was "crafted" by the artist painstakingly placing the individual units using 3D modelling software. Yet here Hayes-Ward acknowledges that her research into cellular automata certainly informed her creative practice ${ }^{7}$ and this is clearly evident in the formal language she has chosen for the bangle. The piece was first rapid prototyped in wax, and then cast in 18 carat gold through the process of lost wax casting.

\section{Justin Marshall, Ceramics}

The artist and designer Justin Marshall explores the use of CAD-CAM and rapid prototyping technologies

(b)

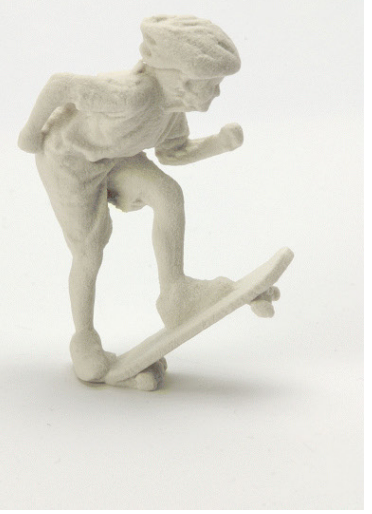

Figure 3.

Karin Sander, Sculpture 1:9,6 (2002) 3D Bodyscans of museum visitors, 3D inkjet printing, plaster powder, pigment. Scale $1: 9,6$, figures approximately $20 \mathrm{~cm}$ tall, Collection Staatsgalerie Stuttgart (Figure 3a). Michaela Finkbeiner, 1:9,63D Bodyscan, 3D inkjet printing, plaster powder (Figure $3 b$ ). Images provided by the artist. 


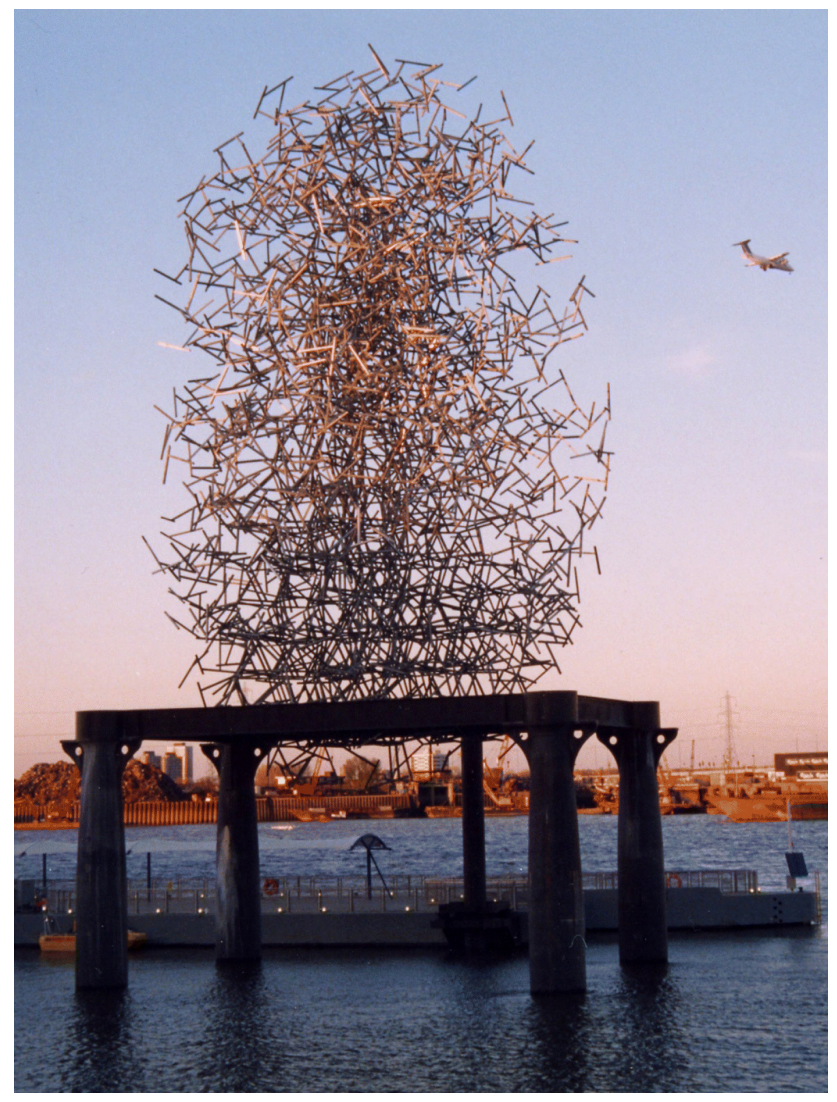

Figure 4

Antony Gormley, Quantom Cloud (1999). The engineering design team of Eliott Wood Partnership and LUSAS Engineering Consultancy Services worked closely with the sculptor to realize the artwork. Image courtesy of LUSAS.

in the development and production of ceramic objects and architectural plasterwork. When describing his creative approach, Marshall emphasizes the central role of experimental "designing through making". ${ }^{8}$ In this context, new software and hardware technologies are employed not as passive modelling tools, but as a medium for active experimentation (Marshall, 2002).

The vessels shown in Figure 9 resulted from a research project in which Marshall investigated the creative possibilities afforded by $3 \mathrm{D} \mathrm{CAD}$ and $\mathrm{LOM}^{9}$ rapid prototyping techniques within ceramic practice. The form of the "Pouring Bowls" was developed using the DeskArtes "Design Expert" 3D modelling software. The stepped or "voxelated"10 surface texture was generated by a low-resolution shelling" operation performed within the software. Such a low-resolution outcome would typically be viewed as unacceptable if smooth surfaces were required; however, Marshall creatively subverts this aspect of the software's functionality, giving the bowls a distinctive and highly attractive visual and tactile quality that would be difficult if not impossible to produce by traditional means. The paper-based LOM rapid prototype process was used to create physical
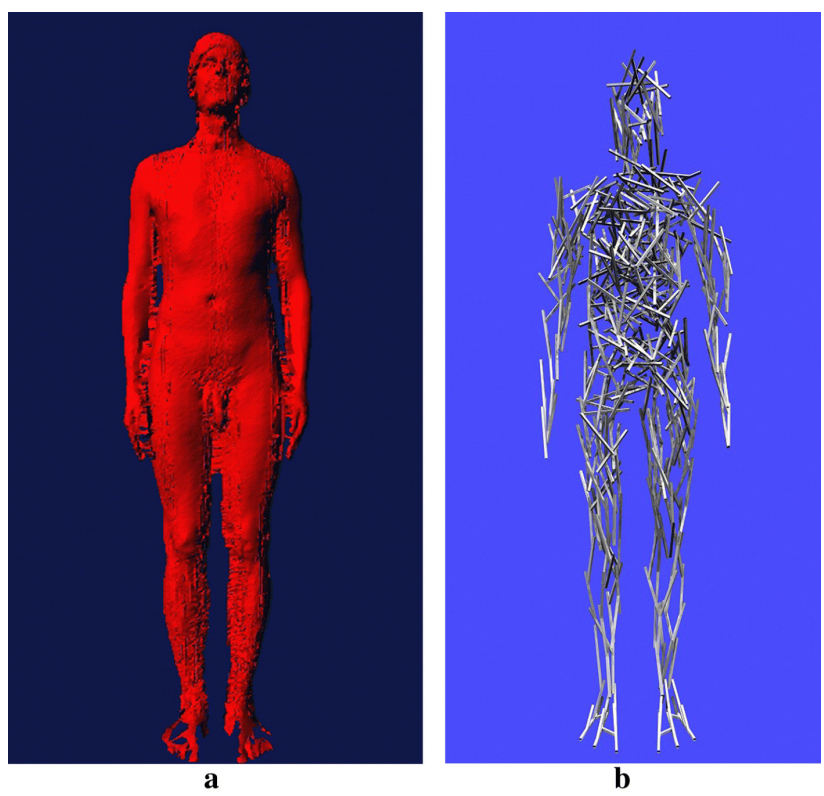

a

b

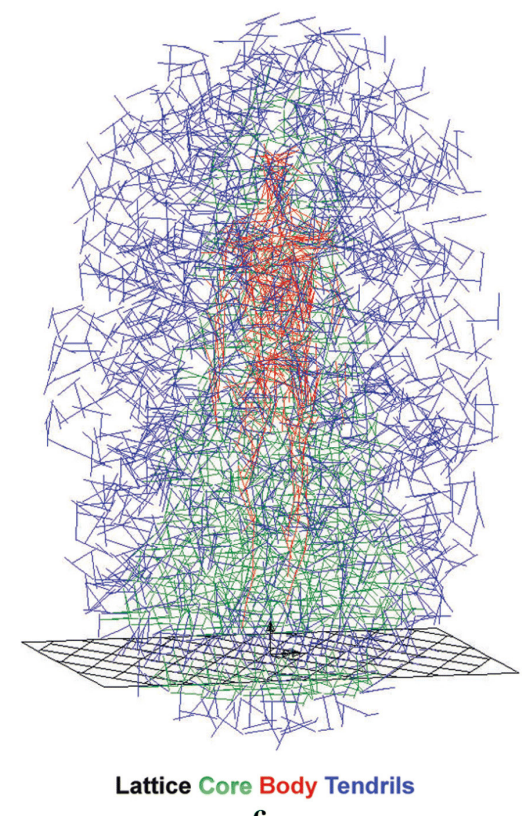

Figure 5.

Antony Gormley, Quantum Cloud (1999). 3D bodyscan (Figure $5 a)$. Human figure (Figure $5 \mathrm{~b}$ ). Fractal lattice structure (Figure $5 c)$. Images courtesy of LUSAS.

"master" models from the 3D CAD data. Moulds were taken from the master models, from which the final ceramic objects could be cast.

Notwithstanding the role of virtual modelling in the generation of the form of the bowls, Marshall emphasizes the essential requirement for the practitioner's hands-on understanding of the physical materials and processes through which the final outcomes will be produced. This practical knowledge is necessary to inform the creative development and to help avoid any problems in the physical realization of the designs. 


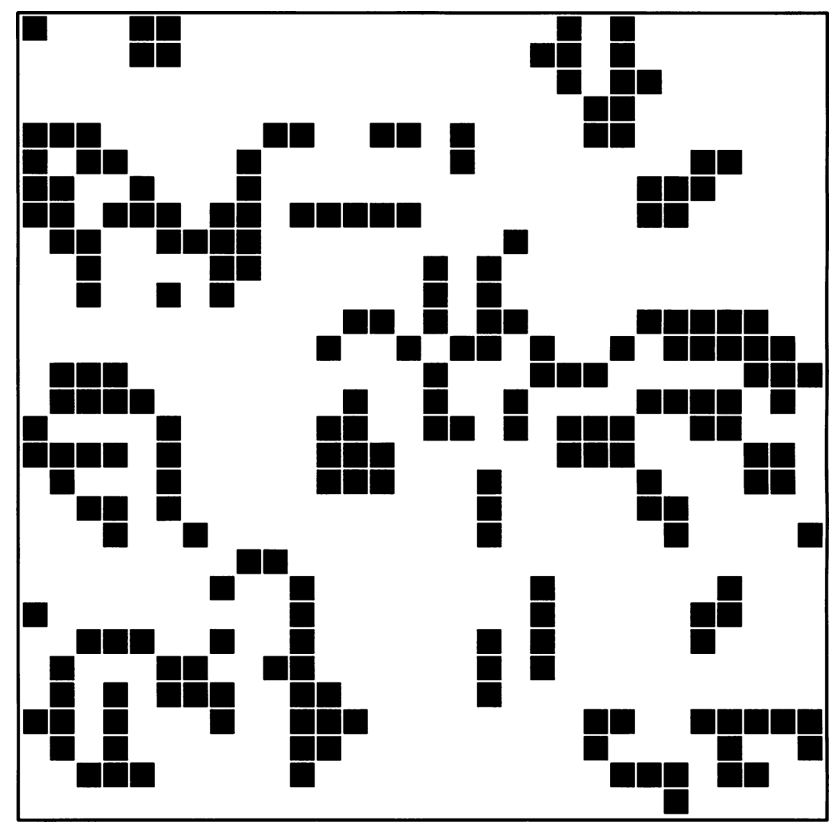

Figure 6.

Conway's Game of Life: Cellular Automata. An example of a generative system which evolves according to mathematical rules.

In a second example, shown in Figure 10, Marshall employed 2D and 3D CAD and computer-controlled milling (CNC) to develop designs for architectural relief tiles and plasterwork based on the "Penrose" tiling system. This project was undertaken in collaboration with Hayles and Howe Limited, an ornamental plasterwork company based in Bristol, UK. Unlike more traditional "periodic" tiling systems, this system is inherently "aperiodic" and creates patterns that never repeat. This allows the creation of an infinite number of patterns from only two basic tiling units and so opens up

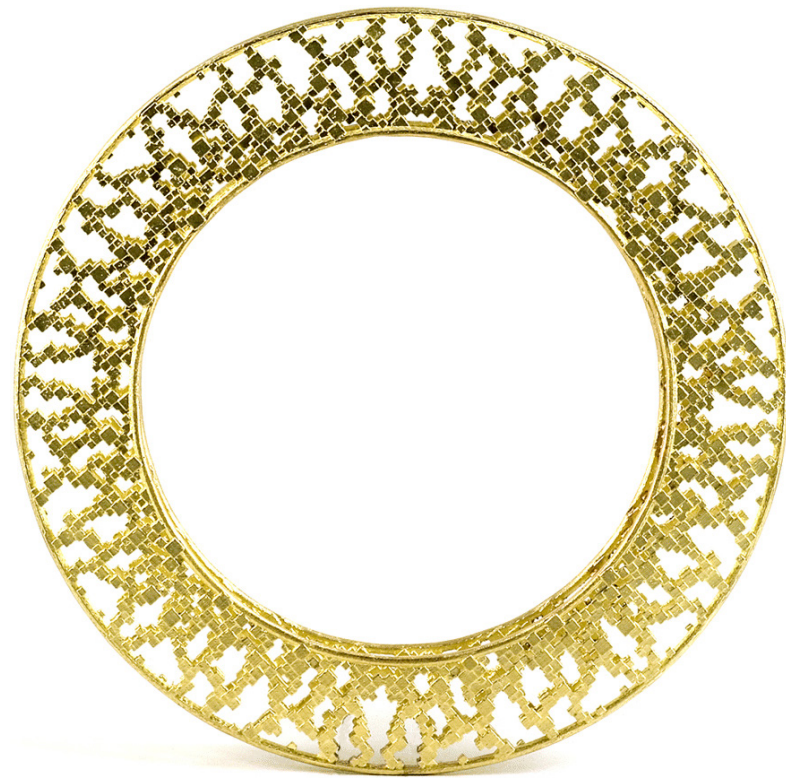

Figure 8.

Jo Hayes-Ward, Bangle. 18 carat gold, produced from a rapid prototype wax master. Image provided by the artist.

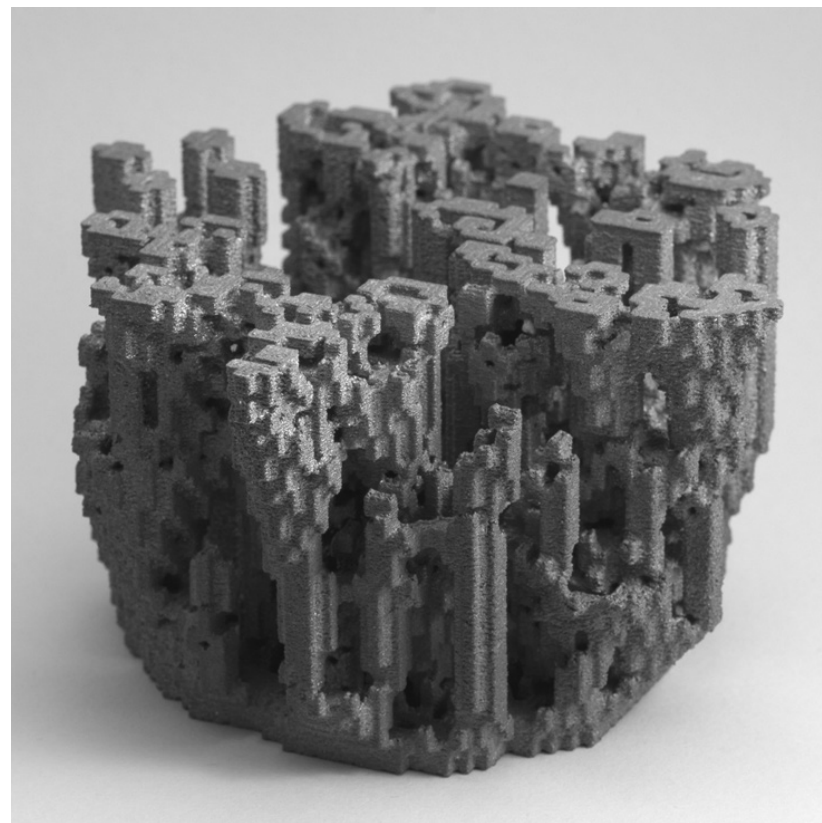

Figure 7.

Jo Hayes-Ward, Sintered City. Made in titanium by selective laser sintering. Image provided by the artist.

the potential for creating unique decorative designs for each customer.

Tiling patterns were first developed and visualized in CAD, after which computercontrolled milling was used to create the tooling profiles that are necessary to produce the "run" plasterwork sections from which the tiling system is composed. Silicone rubber moulds taken from the tile sections are then used to produce finished components.

The assembled system of tiles takes on an organic appearance - not unlike a biological culture viewed though the lens of a microscope - an engaging quality which is present both in the assembled plasterwork itself and in the graphical visualization of the tile layout.

\section{Drummond Masterton, Metalwork}

Drummond Masterton's creative practice centres on the production of novel metal objects, through which he presents an individualistic and highly original approach to the use of CNC (Computer-Numerically Controlled) machining.

In the creation of these artefacts, Masterton demonstrates a level of technical virtuosity equivalent to that of the most highly skilled engineering craftsman. But whilst the skills of the engineering toolmaker are directed towards achieving close mechanical tolerances and smooth surface finishes on mould cavities and dies, Masterton uses industrial CADCAM technologies to create a unique visual and tactile aesthetic, through the 


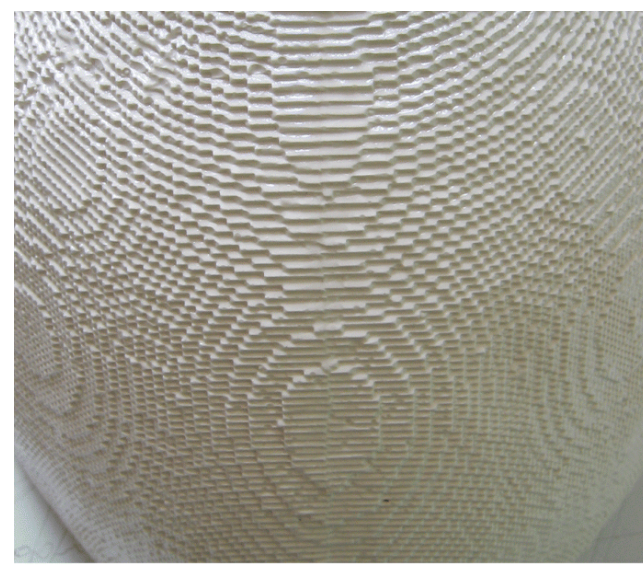

(a)

experimental production of metal objects with complex, exquisitely detailed surfaces (Figure 11).

Masterton has developed and applied a detailed understanding of the relationships between $2 \mathrm{D}$ and $3 \mathrm{D}$ CAD software and CNC milling. He is able to interrogate and modify individual lines of software code controlling the movement of the milling cutter, in order to obtain the specific surface qualities he wishes to create. He describes his own practice as being like that of a craftsman, and his intimate practical knowledge of CAD/CAM technology enables him to retain control of the physical realization of his ideas, rather than relying on a technician to make the translation on his behalf (Masterton, in Jackson, 2007).

Masterton also challenges the paradigm of Time Compression prevalent in the discourses of engineering and industrial design. Here he argues: "CAD software seems to engender a sense of frantic urgency, to explore all possible outcomes while with the same brush failing to establish a strong and rigorous method.... Time for me is one of the most important factors when working with CAD; however it is not the acceleration of time through laboursaving tools, it is the necessity to make time for exploration and reflection with these tools" (Masterton, 2004, n.p.).

From the perspective of traditional craft practice, Masterton's working methods could be considered "hands-off ", since material is manipulated indirectly by machine rather than directly by hand. Yet he utilizes these methods to create captivating objects which embody sensuous formal and textural qualities - the finished artefacts displaying physical characteristics which demand the attention of both eye and hand.

In a final example which follows, the artist Julie Westerman has created a sculptural work that captures
Figure 9.

Justin Marshall, Pouring Bowls (2000). Produced within an AHRB funded research project carried out at Bath Spa University College in 2000 . Images provided by the artist. (b)

dynamic movement, expressed through the motion of cloth under the influence of a "virtual breeze".

\section{Julie Westerman, Drafts/Draughts}

The artist Julie Westerman has created a sculptural representation of a breeze frozen in time (Figure 12). In the work, which was developed using computer animation techniques, the cloth of a cafe' table is blown by a virtual breeze. The animated scene is then frozen, and data from the static virtual model are exported for rapid prototyping, in order to create a miniature sculpture in photosensitive resin by stereolithography. In the realization of the artwork, Westerman worked with specialists in computer graphics and rapid prototyping technologies.

Westerman acknowledges that, in sculpture, the representation of cloth has a long history - she identifies that in classical works of art drapery was often used to signify human scale, or to add a sense of sumptuous grandeur. She also points towards the more playful association of the magician's cloak, or conjuror's cloth, where the audience wonders what may lie beneath:

... A dove? A rabbit? There is the moment of ta da! And suddenly all is revealed. (Westerman and Lee, 2006, p. 4)

For this artwork, Westerman explores what is perhaps a magical idea: "I have been intrigued by the problem of representing the movement of cloth in a single moment." She describes how the flowing movement of virtual cloth, defined by the mathematical rules within the animation software, appeared to be "unexpectedly sexual, saucy and completely mesmerizing: an organic form constructed wholly from digital reference points" (Westerman and Lee, 2006, pp. 4, 6).

Westerman's creative practice engages with new technological processes, and, by doing so, she explores and articulates ideas which might otherwise 
be impossible to realize. This enchanting work brings together physical and virtual worlds, through static and dynamic representations of the artwork.

\section{DISCUSSION}

This paper has examined work by practitioners in art and design who have creatively engaged with digital design technologies, including CAD-CAM, rapid prototyping

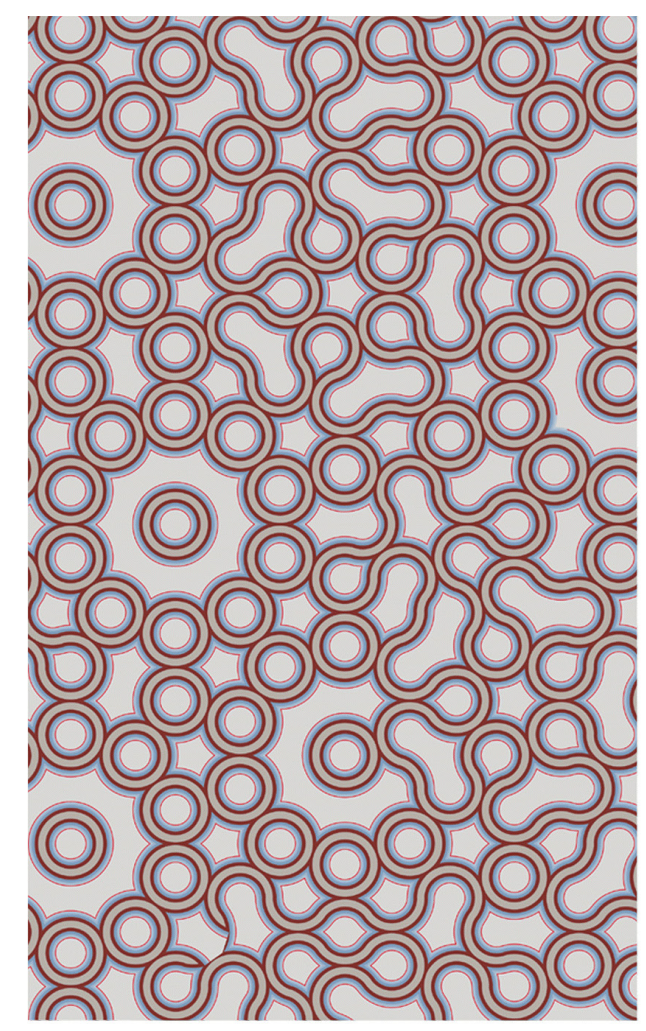

(a)

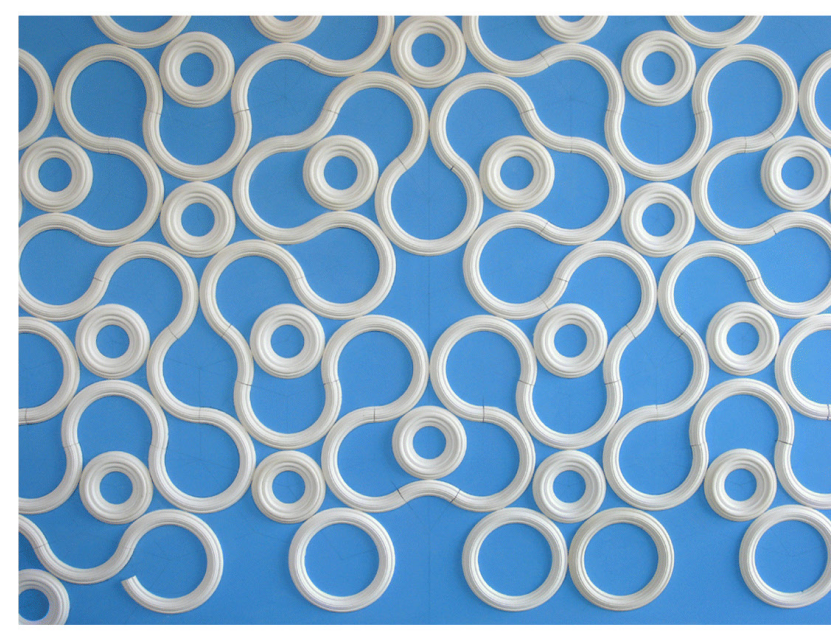

(b)

Figure 10.

Justin Marshall, aperiodic plasterwork relief, 2006. Project undertaken in collaboration with Hayles and Howe Limited, an ornamental plasterwork company, based in Bristol, UK. Funding for this project was obtained from University College Falmouth, Arts \& Business \& Arts Council England.
(3D printing), and 3D scanning. The examples clearly demonstrate that as these technologies become increasingly widespread, they continue to open up new creative possibilities in areas of practice outside mainstream industrial design and manufacturing contexts. Furthermore, the paper serves to show how artists and design practitioners can connect with technical specialists from other disciplines, for example, engineering and computer animation.

This can lead to new creative synergies, resulting in interdisciplinary practice that is innovative both in process and outcomes - whereby art and design practitioners productively engage with specialists in other fields, drawing on their knowledge, skills, and techniques in the realization of work made possible through this engagement.

Examples described in this paper display qualities which would be difficult if not impossible to achieve without the use of the new technologies, and in this way they appear to embody the expression "otherwise unobtainable" that was coined by the art historian Tanya Harrod (Harrod, 2007). That is not to say that the examples represent mere technical exercises, since here the aesthetic sensibilities of creative makers are brought to bear in work which extends the boundaries of practice in art and design disciplines.

Earlier it was identified that some critics might view computer technologies as presenting a threat to human creativity and experience. However, work by art and design practitioners presented here demonstrates that the new design technologies enable forms of making which can provide ample possibilities for creative expression. As Heidegger suggested in The question concerning technology - as well as danger, a saving power can also be found in technology. In his discussion of techne and poiesis - poetic making - Heidegger pointed to the special role the arts might play in showing the way to this saving power.

Work by some artists may challenge us to question our own relationship to technology (Hohl, 2006). For example, Antony Gormley describes his Quantum Cloud sculpture as a "Dematerialized Monument" in which the form of the human body is opened up and dispersed within random matrices of connecting elements (Gormley, 2007, pp. 283, 363; Noble, 2007, p. 45). Here we may be prompted to consider how such a work might reflect our place in today's world of hypermodern technologies, as the human figure appears to dissolve into a complex cloud of energy or interconnected data. 


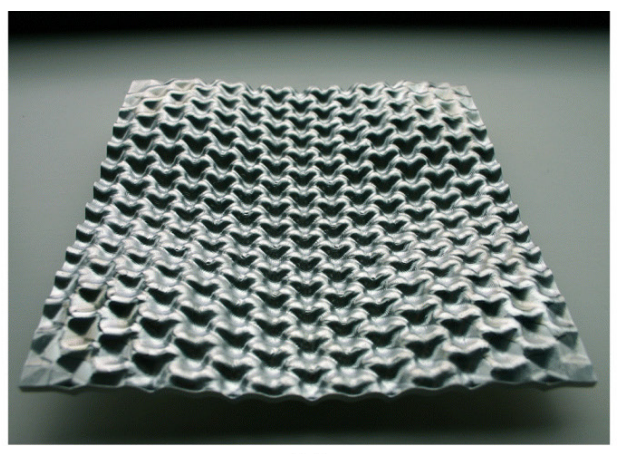

Figure 11.

Drummond Masterton, Metalwork. Hexabubble bowl (Figure 11a), Whisky Cup (Figure 11b), ST 14 (Figure 11c). CNC machined aluminium. Images provided by the artist.

(a)

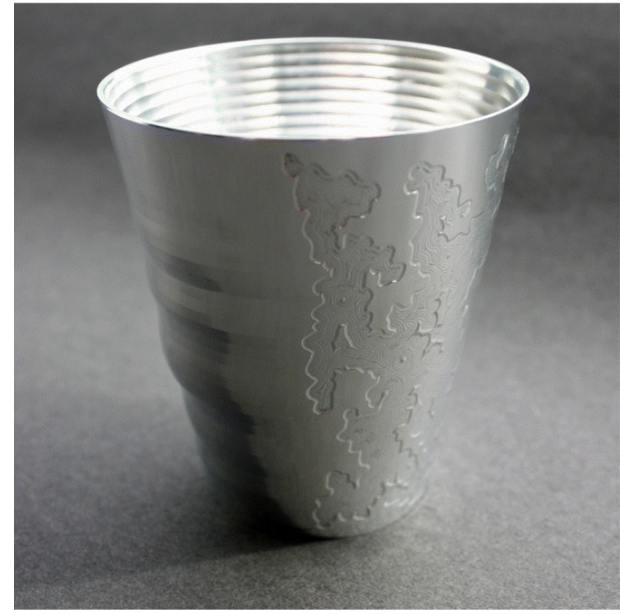

(b)

Through poetic making, creative practitioners can explore and critically reflect on how emerging technologies present new ways of revealing the world. One practical example is how the increasing availability of 3D scanning, together with 3D printing, is beginning to bridge the gap between physical and virtual making. Using 3D scanning, the geometry of physical prototypes such as hand-made maquettes, as well as existing artefacts, can be captured and then imported into 3D modelling software for further creative development, the results being made physical once again through rapid prototyping or computer-controlled machining. Such developments open up new possibilities for hybrid forms of practice, encompassing creative making in both physical and virtual worlds. Could it be that the twentieth-century notion of "truth to materials" in relation to the arts and crafts may now even - in the twenty-first century - extend to one of "truth to virtual materials"?

By its original meaning poetry means simply creation, and creation, as you know, can take very various forms. Any action which is the cause of a thing emerging from non-existence into existence might be called poetry, and all the processes in all the crafts are kinds of poetry, and all those who are engaged in them poets. (From Plato12 “The Symposium", trans. Hamilton, 1951, p. 85)

\section{ACKNOWLEDGEMENTS}

The authors are grateful to Karin Sander, Lusas Engineering Consultancy Services, Jo Hayes-Ward, Justin Marshall, Drummond Masterton, and Julie Westerman, who offered insights into their own creative practice and provided images of work included in this paper.

Jo Hayes-Ward, Justin Marshall, and Drummond Masterton gave presentations of their work at “Digital Explorers 2", Metropolitan Works, London, in March 2007 - an event presented by the 3D Digital Production Research Cluster, University College Falmouth and Metropolitan Works, London.

The first author's research is funded by an Academic Fellowship from Research Councils UK (RCUK).

\section{NOTES}

1. Computer Aided Design and Computer Aided Manufacturing.

2. For example, see the industry journal Time Compression Technologies (Rapid News Publications), also Evans (2002).

3. "a personal and subconscious intelligence, linking hand and brain" (Bunnell, 2000 after Polanyi, 1969). See also Cooley (1980) and Rust (2004). Rust suggests how tacit knowledge might be invoked and put to use in processes of creative discovery and invention.

4. Cooley refers to Braverman (1974).

5. Or voxel-like. In computer graphics, a voxel is the threedimensional equivalent of a pixel.

6. Paolozzi explored the relationship between art and technol- 

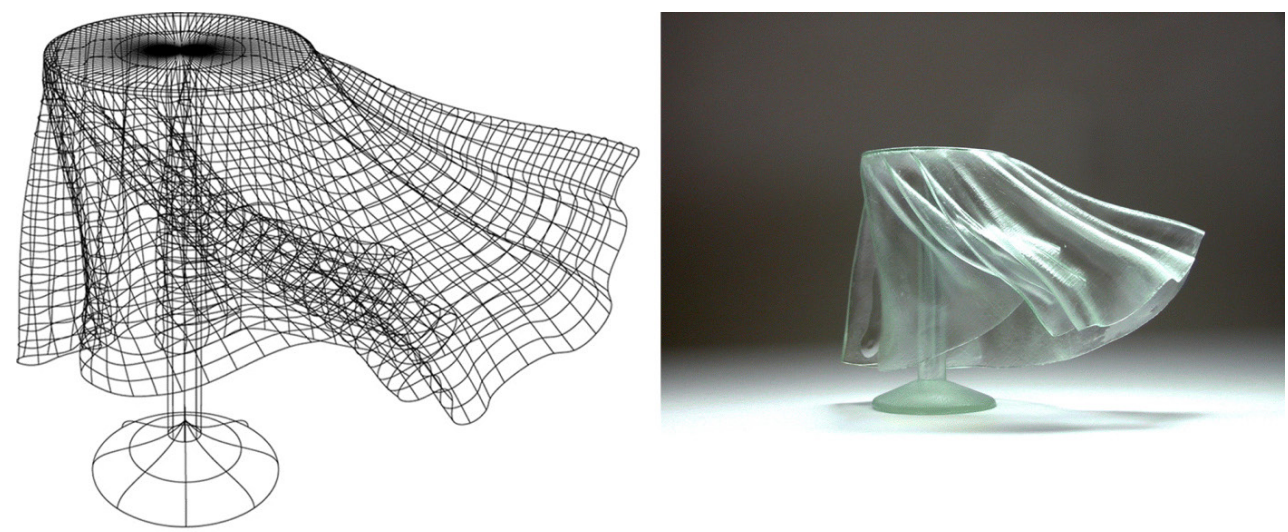

Figure 12. Julie Westerman: Drafts/Draughts. Wireframe models from stills taken from the animation software (Figure 12a, 12b). Stereolithography model in photopolymer resin (Figure 12c). Inter ... Exhibition at the Harris Museum and Art Gallery, Preston (2004). Images provided by the artist.
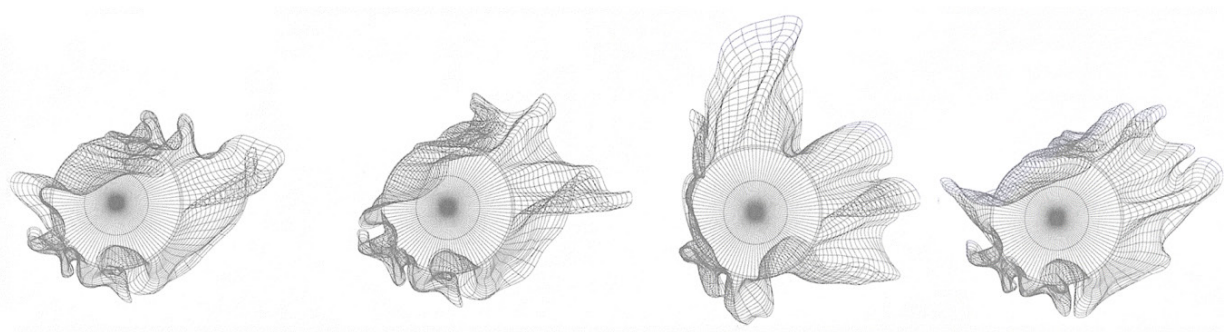

(b)

ogy, and the interface between people and machines, in sculptures which have been described as "totems for the technological age" (Obituary: Sir Eduardo Paolozzi, Daily Telegraph, 23 April 2005)

7. Author's correspondence with the artist Jo Hayes-Ward, March 2007.

8. See also Bunnell (2000).

9. LOM Layered Object Manufacture, in which paper layers corresponding to the cross-sectionalshape of the object are automatically cut,stacked, and bonded together to form a physical prototype.

10. In computer graphics, a voxel is the basic cubic unit from which a $3 \mathrm{D}$ object is made the $3 \mathrm{D}$ equivalent of a pixel. To voxelate means to represent a $3 \mathrm{D}$ object as an array of cubic units.

11. A function of the software that is used to make solid forms hollow.

12. Heidegger cites this passage as "Every occasion for whatever passes beyond the nonpresent and goes forward into presencing is poiesis, bringing- forth [Her-vo-bringen]" (Heidegger, 1954, trans. Lovitt, p. 317)

\section{REFERENCES}

Baese, C. (1904). Photographic process for the reproduction of plastic objects. US Patent 774, 549: 1904.

Baudrillard, J. (1996). Baudrillard on the New Technologies: An interview with Claude Thibault (S. Falcone, Trans.). European Graduate School. Retrieved September 18, 2007, from http:// www.egs.edu/faculty/baudrillard/baudrillard-baudrillardon-the-new-technologies.html

Beaman, J. J., Barlow, J. W., Bourell, D. L., Crawford, R. H., Marcus, H. L. \& McAlea, K. P. (1997). Solid freeform fabrication: A new direction in manufacturing with research and applications in thermal laser processing. Norwell, MA: Kluwer Academic Publishing.
Beistegui, M. de (2005). The new Heidegger. London and New York: Continuum.

Braverman, H. (1974). Labor and monopoly capital. The degradation of work in the 20th century. New York: Monthly Review Press.

Bunnell, K. (2000). Designing through making. Design Journal, 3(3), 1-3.

Bunnell, K. (2004). Craft and digital technology. Keynote address at World Crafts Council 40th Anniversary Conference, Metsovo, Greece, 2004. Retrieved February 8, 2008 from http://www.autonomatic.org.uk/team/kb/index. html

Collins, J. \& Selina, H. (1999). Introducing Heidegger. New York: Totem Books.

Cooley, M. (1980). Architect or bee? The human technology relationship. Langley Technical Services. Slough: Hand and Brain Publishers.

DeGrandpre, R. (2001). The great escape. Adbusters, March/ April, 21-31.

Evans, M. (2002). The integration of rapid prototyping within industrial design practice. PhD Thesis, Loughborough University.

Evans, M. A. (2004). An investigation into the capabilities of a virtual workshop. Journal of Design and Technology Education, 9(1), 6-13.

Evans, M. A., Wallace, D., Cheshire, D. G., \& Sener, B. (2005). An evaluation of haptic feedback modelling during industrial design practice. Design Studies, 26(5), 487-508.

Gardner, M. (1970). Mathematical games: The fantastic combinations of John Conway's new solitaire game "life". Scientific American, 0ctober, 120-123. 
Gilbert, N. \& Troitzsch, K. G. (2005). Simulation for the social scientist (pp. 130-133). New York: McGraw-Hill International/Open University Press.

Gormley, A. (2007). Antony Gormley. London: SteidIMACK.

Harrod, T. (2007). Otherwise unobtainable: the applied arts and the poetics and politics of digital technology. In S. Alfoldy (Ed.), Neocraft: Modernity and the crafts. Halifax, NS: Press of Nova Scotia College of Art and Design.

Hayes-Ward, J. (2007). Statement from the artist's website. Retrieved September 18, 2007 from www.johayesward.co.uk

Heidegger, M. (1954). The question concerning technology. From Vorträge und Aufsätze (W. Lovitt, Trans.). In D. Farrell Krell (ed.) (2002), Basic writings: Martin Heidegger. London: Routledge.

Heidegger, M. (1951). Building dwelling thinking. In Poetry, language, thought (A. Hofstadter. Trans.), (2001). New York: HarperCollins.

Hodges, M. (1998). It Just Feels Right. Computer Graphics World, 21(10), 48-56.

Hohl, M. (2006). This is not here: Connectedness, remote experiences and immersive telematic art. $\mathrm{PhD}$ Thesis, Sheffield Hallam University, UK. Available from http://www. hohlwelt.com/downloads/mhohl-phdthesis.pdf.

Jackson, L. (2007). Autonomatic. In Autonomatic: 3D digital production research, University College Falmouth. Exhibition catalogue. Falmouth: University College Falmouth. Available from http://www.autonomatic.org.uk

Jacobs, P. F. (1992). Rapid prototyping and manufacture: Fundamentals of stereolithography. Dearborn, MI: Society of Manufacturing Engineers.

Koivisto, H. (2007). Karin Sander biography. Popcorn and politics: Activists in art. Retrieved March 22, 2007 from: www.kiasma.fi/site/pop/pop. php?langen\&haku\&tid1059\&printit

Marshall, J. (2002). Computer technology and creative practice. Ceramics Technical, 14, 47-50.

Masterton, D. (2004). The hunt for complexity. University College Falmouth. Retrieved July 10, 2007, from http://www. autonomatic.org.uk

McCullough, M. (1998). Abstracting craft: The practiced digital hand. Cambridge, MA: MIT Press.

Milroy,M. J.,Weir, D. J. Bradley, C. \& Vickers, G. W. (1996). Reverse engineering employing a 3D laser scanner: A case study. International Journal of Advanced Manufacturing Technology, 12(2), 111-121.

Noble, R. (2007). The utopian body. In Michael Mack, ed., Antony Gormley. London: Steidl- MACK.

Plato (1951). The symposium (W. Hamilton, Trans.). Harmondsworth: Penguin Classics.

Polanyi, M. (1969). Personal knowledge. London: Routledge.

Press, M. (1996). To bee or not to bee. Co-Design (78), 94-97.

Rust, C. (2004). Design enquiry: Tacit knowledge and invention in science. Design Issues, 20(4), 76-85.

Sander, K. (2007). Statement from the artist's website. Retrieved October 1, 2007, from http://www.karinsander.de/ index.php?page/en/w_196_text.html
Sener, B., Wormald, P., \& Campbell, I. (2002). Towards “virtual clay modelling" challenges and recommendations: A brief summary of the literature. In Proceedings of Design 2002, Dubrovnik May 14-17, 2002.

Shillito, A. M.,Wright, M., \& Gauldie, D. (2004). The TACITUS experience: A new spatial, multi-sensory digital interface supporting creativity. In Proceedings of Pixel Raiders 2, Sheffield Hallam University, April 6-8, 2004 (CD ROM).

Sobieszek, R. A. (1980). Sculpture as the sum of its profiles: Francois Willeme and photosculpture in France, 1859-1868. Art Bulletin, 62(4), 617-630.

Spiller, E. (2007). Foreword. In Autonomatic: 3D Digital production research, University College Falmouth. Exhibition catalogue. Falmouth: University College Falmouth. Available from http://www.autonomatic.org.uk

Unver, E., Atkinson, P., \& Tancock, D. (2006). Applying 3D scanning and modelling in transport design education. Computer-Aided Design and Applications, 3(14), 41-48.

Virilio, P. (2000). The information bomb. London: Verso.

Walters, P., Chamberlain, P., Press, M., \& Tomes, A. (2004). Designing by numbers? Keeping the human in humancentred design. In Proceedings of Pixel Raiders 2, Sheffield Hallam University, April 68, 2004.

Westerman, J. \& Lee, J. (2006). Draft/draughts. From the series Transmission: The Rules of Engagement. London: Artwords Press.

Weynants, T. (2008). Early visual media: The photosculpture of François Willème. Retrieved 14 March 2008 from http:// www.visual-media.eu/photosculpture.html. Weynants cites the source of the illustration by N. Lambert and H. Massieu as being the Collection of Henri Koilski.

\section{CORRESPONDENCE}

Peter Walters, PhD, Research Fellow, University of the West of England,

Bower Ashton Campus,

Kennel Lodge Road,

Bristol BS3 2JT, UK.

E-mail: Peter2.Walters@uwe.ac.uk

Published online 14 August, 2008

ISSN 1749-3463 print/ ISSN 1749-3471

DOI: 10.1080/17493460801980016

(C) 2007 Artifact 